\title{
El folleto jurídico y la colección de la Escuela Libre de Derecho
}

Jaime del Arenal Fenochio

ESCUELA LIBRE DE DERECHO

\begin{abstract}
Rescata el valor del folleto como fuente histórica y reseña el valor de la colección de los materiales custodiados en la Biblioteca de la Escuela Libre de Derecho.
\end{abstract}

$\mathrm{E}$ s muy satisfactorio intervenir en una sesión de trabajo donde, desde perspectivas diferentes, se reflexiona acerca de la importancia de la folletería para la investigación, en este caso particular, historiográfica. Hace diez años publiqué un artículo donde pretendí llamar la atención acerca de las enormes posibilidades que brindaba el estudio de los folletos jurídicos mexicanos para el cabal conocimiento de la historia del derecho de nuestro país. ${ }^{1}$ Sin embargo, en esa

1 Arenal, "Hacia", 1987, pp. 79-116. ocasión apunté que dichas posibilidades no sólo se reducían a la ciencia jurídica, sino que también tenían relación con la biografía, con las mentalidades colectivas, con la historia de la imprenta-especialmente la de los estados-, e incluso con la geografia. Los folletos jurídicos que en esa ocasión analicé, tenían que ver fundamentalmente con litigios o procesos civiles, en particular relacionados con el tema de la propiedad; sea a través de pleitos sucesorios o de litigios relacionados con la propiedad inmueble, la gama de temas incluidos en los folletos jurídicos obviamente no se agota en estos 
temas. Asuntos penales, penitenciarios, familiares, políticos, administrativos, fiscales, constitucionales, etc. son contemplados una y otra vez, y en ocasiones uno tras otro, como para permitir la reconstrucción de sonados asuntos o causas célebres. ¿No lo demuestran así los folletos relacionados con ese famoso pleito Amor $v s$. Escandón?, ¿o los que permitieron a Martín Díaz su valioso análisis sobre el caso Tlahualilo y el aprovechamiento de las aguas del río Nazas, ${ }^{2}$ al que tanta importancia dio Bulnes como una de las posibles causas del rompimiento del gobierno gringo con el de Porfirio Díaz ${ }^{3}$ y que enfrentó en el foro a esas dos personalidades jurídico-políticas que fueron Luis Cabrera y Jorge Vera Estañol, antes de que se enfrentaran en la Escuela Nacional de Jurisprudencia para dar origen a la propia Escuela Libre de Derecho? ¿O los que mencionó Rafael Diego Fernández en su estudio sobre José Diego Fernández? ${ }^{4}$

La biobibliografía de juristas destacados - como intenté hacerlo con la de Jacinto Pallares-, ${ }^{5}$ y las que tendría que hacer el que pretendiera escribir las biografias de Agustín Rodríguez, de Rodolfo Reyes o de otros no menos importantes letrados, cuyas obras constan casi todas en folletos, dificilmente podrian hacerse sin consultar las misceláneas que los contienen. Es posible descubrir toda una gama de facetas

2 Diaz, "Litigio", 1990, pp. 129-194.

3 Bulnes, Verdadero, 1920 , pp. 268-275.

${ }^{4}$ Diego, "Constitución", 1993, pp. 139-197.

5 Arenal, "Jacinto", 1989, pp. 197-226. También en Pallares, 1992, pp. 143-183. Menciono más de treinta folletos y no más de diez libros desconocidas tan sólo con la simple lectura de los larguísimos títulos de los folletos jurídicos. ¡Cuanto más de la lectura de sus contenidos!

En esta ocasión es pertinente repetir algo de lo que en aquella publicación escribí:

Desde luego, a quienes puede resultar más interesante el conocimiento del folletín jurídico es a los curiosos de la evolución del derecho en México, toda vez que su contenido arroja importantes luces sobre prácticamente cualquier problema relativo a la vida de aquél. Responsabilidades de funcionarios públicos, conflictos familiares, cuestiones constitucionales, nombre $\mathrm{y}$ actuación de los abogados de la época, informes de autoridades, conflictos entre los estados o entre poderes, delitos y delincuentes, marcha de las escuelas de derecho, operaciones mercantiles, testamentarías, herencias, literatura jurídica leída en el país, el impacto de la codificación, invasión de capitales extranjeros y privilegios concedidos a éstos en tal o cual rama de la industria son, entre otros muchos asuntos que vemos reflejados en esta forma de literatura que dio asilo a multitud de informes, estudios, tesis profesionales, sentencias, leyes, reglamentos, estatutos, pedimentos, demandas, lecciones, alegatos, proyectos, amparos, memorias, iniciativas, defensas, disertaciones, formularios, instrucciones, apuntes y documentos, y que en la mayor parte de los casos, se encuentra sin orden ni concierto recogida en los tomos que, bajo los rubros de piezas diversas, papeles en derecho, folletos juridicos, alegatos, jurisprudencia, o el más socorrido de misceláneas, se mal conservan en las diversas bibliotecas jurídicas - públicas y privadas- del país. 
La atención que los interesados en el siglo XIX mexicano pongan en la folletería jurídica no puede verse defraudada ya que, además de constituir una magnífica fuente para el conocimiento del derecho de la época, contribuye a esclarecer cuestiones que rebasan el estricto campo de lo jurídico: antecedentes, adquisiciones y traspasos de propiedades, funcionamiento de instituciones educativas, relaciones entre la Iglesia y el Estado, formas de razonar y de escribir, estilo oratorio, constitución de sociedades mercantiles, asuntos familiares o genealógicos, actuación de personajes célebres, etcétera.

[...] al margen de cualquier utilidad que aporte a los historiadores del derecho, el contacto con la folletería juridica constituye un modo de acercarse más al conocimiento de la historia del país, de la región, del pueblo, de la familia o del personaje[...]

El vacío producido por la falta de colecciones de jurisprudencia local, o de archivos judiciales, puede ser lienado, aun sea en mínima parte, por la documentación que celosamente guardan los folletos relacionados con procesos judiciales, como complementan la historia de diversas instituciones culturales o educativas los folletos que recogen sus estatutos, sus informes periódicos o los discursos conmemorativos en ellas pronunciados.

En fin, la riqueza de este tipo de impresos rebasa a su propio contenido para extenderse a la meramente bibliográfica, pues al consignar y recoger en sus líneas asuntos particulares de quienes financiaron o solicitaron su impresión, por regla general el número de ejemplares editados es muy reducido, constituyéndose algunos en piezas de valor bibliográfico inestimable. ${ }^{6}$

${ }^{6}$ Arenal, Pallares, pp. 80-82.
Para otras ideas vertidas en esa publicación remito al interesado a su lectura. Ahora interesa subrayar algunas otras consideraciones $y$, sobre todo, prolongar hasta nuestros días las reflexiones en torno a ese tipo de impreso muy peculiar que, como todo, se transforma mediante la desaparición de géneros y la proliferación de nuevos contenidos y objetivos, lo que implica, por fuerza, el cambio de autores y de destinatarios. No menos importante es dar a conocer la valiosa colección de folletería - no sólo jurídica- que conserva la biblioteca de la Escuela Libre de Derecho, que cada día atrae con mayor frecuencia la atención de historiadores mexicanos y extranjeros debido, no cabe duda, a su impronta decimonónica.

En aquella ocasión, mi interés partió de tres evidencias con las cuales topé mediante el contacto diario con la rica folletería de la biblioteca de la Escuela Libre: una, el hecho de que prácticamente ninguna bibliografia especializada en derecho -antigua o más o menos reciente-contemplaba ni en mínima parte al folleto juridico; ${ }^{7} \mathrm{se}$ gunda: que el número de éstos era tan impresionante que aquéllas resultaban inútiles e insuficientes para un historiador del derecho, de las instituciones o de las ideas juridicas, y tercera: que, dada su escasez y poco tiraje, si no se emprendía una pronta labor de rescate y de concientización del valor de la folletería jurídica, ésta se perdería irremisiblemente... o cuando me-

${ }^{7}$ Excepto, de algún modo modesta, la de Manuel Cruzado, Véase Arenal, "Hacia", 1987, p. 79 , n. 1 . 
nos se dilataría hasta fecha incierta su aprovechamiento. Mucho y desconocido material contienen esta clase de impresos que hoy nos ocupa, como para pretender desdeñarlo en la tarea de la reconstrucción de nuestro pasado jurídico. Al conjunto de leyes -las generales varias veces recopiladas en voluminosas colecciones como la de Dublán y Lozano, o locales como la de Corominas para Michoacán-, monografias doctrinales y sentencias judiciales - $y$ andando el tiempo revistas o periódicos especializados- que podian obtenerse en bibliotecas o archivos judiciales y notariales, se debían sumar los miles y desconocidos folletos que dormían pegados unos a otros al amparo de esos volúmenes de misceláneas que adornan -las más de las veces sin ninguna utilidad- los acervos bibliográficos especializados en derecho, tanto públicos como de particulares.

El mero acercamiento a sus títulos reveló de inmediato el nombre de juristas y abogados hasta entonces ignorados; títulos de obras desconocidas de otros muy afamados; sitios, imprentas y familias de las que se tenía nula o poca noticia, y permitió enriquecer nuestra visión de los conflictos de una época de transición entre dos órdenes jurídicos desde la perspectiva del conflicto entre intereses privados; de la causa penal que afectaba a una o más personas, del discurso del abogado pronunciado en la inauguración de cursos de una escuela de derecho; de las sesiones de una academia teóricopráctica de legislación; de la iniciativa legal malograda; de la sentencia judicial; del amparo interpuesto; del recla- mo de los pueblos, o de las resistencias a una política secularizante por parte de una sociedad nada secularizada.

En el folleto se apreciaron las dificultades de la legislación para imponerse como única y soberana fuente del derecho, así como la resistencia ofrecida tanto por la jurisprudencia -entendida como derecho de juristas- como por la costumbre para desaparecer frente al ascenso de aquélla. El despertar de los intereses individuales y la consagración de la propiedad como "derecho natural" eran cosas que la lectura del folleto jurídico fácilmente revelaba; no menos que la acción y el discurso de los abogados, jueces y procuradores, que de repente conocíamos e identificábamos, o el peso de la opinión pública considerada en definitiva como inapelable sentencia, por encima incluso de la opinión judicial. Transición entre dos órdenes jurídicos, uno plural, más bien tópico y favorecedor del arbitrio judicial y de la argumentación autorizada; el otro -el moderno-absolutista, sistemático, esclavizador del juez y totalmente legalista.

Hoy, ciertamente, el folleto procesal, es decir aquel que contiene un alegato forense o una sentencia - el que analicé en dicho estudio-, prácticamente ha desaparecido. A nadie parece importarle ya ventilar los pleitos propios ni enterarse de los ajenos. La opinión pública pesa cada vez menos tratándose de intereses particulares y ya no se vale del folleto. Este ha clejado de ser utilizado como forma de presión social. Los nuevos folletos jurídicos recogen discursos, acciones de 
gobierno, propaganda; sirven de medios masivos de difusión de campañas de muy diversa índole y contienen los informes de autorizados burócratas de altos vuelos; dan cuenta de breves estudios que se quedaron a la mitad del camino de llegar a ser libros, o anuncian eventos, programas y currícula académicos. En todo caso, y a diferencia de los del siglo XIX, ahora se producen masivamente, $y$ pretenden llegar a un público mayor pero más perezoso para la lectura, y totalmente desinteresado en la justicia, por lo que, al igual que sus ancestros, tienen permanencia efimera y casi siempre terminan en el bote de la basura. Son incluso menospreciados por lectores y bibliotecarios a quienes quita tiempo y esfuerzo frente al cúmulo de revistas y libros que día a día llegan a los acervos bibliográficos. Una buena parte de ellos lo forman las "separatas" de los artículos publicados en las revistas, y la mayoría de las veces son producciones anónimas. Ni el jurista ni el abogado acude ya a ellos salvo en excepcionales circunstancias. Hoy en fin, el folleto jurídico no fustiga, ni exhibe, ni condena o absuelve..., ni es resultado de la inteligencia del jurista. Como hijo de una época dominada por la información sólo pretende informar, y esto, en forma efimera. Al no tener altos vuelos académicos no merece el respeto de investigadores, y es despreciado por bibliotecarios que bien a bien no saben ya qué hacer con tanta publicación.

No ocurrió así en el pasado, y de aquí que para el historiador sean un instrumento muy valioso que le deparará con toda seguridad insospecha- das sorpresas. La sociedad decimonónica, y la que vivió los primeros treinta años de este siglo, se refleja en buena medida y cabalmente en sus folletos jurídicos.

Todas estas y otras cosas pudimos apreciar en aquel primer acercamiento a una folletería que hasta entonces no había atraído la atención de nadie, ni aquí ni en los estados de la república, no obstante que algunas colecciones ya estaban muy bien catalogadas, como las muy afamadas de la Biblioteca Pública de Guadalajara o la colección Lafragua de la Biblioteca Nacional. 8

Hoy las cosas han cambiado; la prueba es esta reunión. El medio académico se ha sensibilizado y parece haber rescatado de una vez y para siempre el valor de la folletería jurídica como instrumento bueno y representativo para acercarnos al estudio de muy diversos temas y, en particular, de aquellos que tocan de cerca los conflictos humanos y sociales.

Es pertinente agregar algo acerca de otro repositorio donde se conserva una buena cantidad de folletos jurídicos decimonónicos. En efecto, aquel primer trabajo resultó ser la consecuencia de una tarea de rescate, emprendida por mí, de los miles de folletos que se encontraban almacenados sin ton ni son en la biblioteca de la Escuela Libre de Derecho; algunos previamente agrupados en misceláneas; los más, dispersos. El detonador de esta tarea de rescate, como en muchas

${ }^{8}$ Dorante, Inventario, 1978; Moreno, Catálogo, 1975. 
otras cosas, fue el terremoto del 85 , que destruyó algunas buenas bibliotecas o dispersó otras, como la que poséia el dueño de aquella espléndida papelería Génova, que se encontraba en la calle de Chiapas de la colonia Roma y cuya valiosísima sección juridica adquirió el despacho Creel Abogados. Incluía una no menos rica colección de folletos jurídicos - muchos del siglo XIX- que al despacho no le interesaron, y que generosamente donó a la escuela. De esta forma, la colección de folletos que ya para entonces poséa ésta, se vio súbitamente aumentada y enriquecida con aquel material que estuvo en un tris de convertirse en pulpa de papel por un malentendido: del fondo de una bodega de papeleros la tuve que rescatar casi a punto de que fuera devorada por las fauces de las máquinas destinadas a reciclar papel. iAhora que lo recuerdo, todavía siento la rabia y los escalofríos que entonces sentí! ¡Lo que se hubiera perdido! Hoy la colección goza de buena salud, se formaron con sus folletos más de 150 gordas misceláneas bien empastadas y que se encuentran en proceso de clasificación electrónica. Junto con los folletos que ya se tenían y los que han seguido adquiriéndose, forman toda la sección de Misceláneas de la biblioteca de la Libre, sin duda, una de las más importantes de todo el país. Arriba he mencionado tres estudios publicados en la Revista de Investigaciones Jurídicas de la propia Escuela Libre de Derecho que fueron hechos a partir del examen de la folletería relativa que ahí se conserva, lo que habla de su utilidad e importancia.
La forman 293 volúmenes de misceláneas con un total aproximado de 5000 folletos. Los más antiguos son de la década de los veinte del siglo XIX, y aunque no todos son estrictamente jurídicos, sí la inmensa mayoría. Algunos repiten informes publicados en revistas o diarios, pero casi ninguno pasó de la calidad de folletos, y por lo mismo son ejemplares raros o únicos. Una historia de la imprenta y de la literatura jurídica que no los tome en cuenta estaría dejando fuera una de las principales expresiones del saber jurídico de una época rica en ideales de justicia y creyente todavía en la ley y en el derecho. Tampoco se explicaría, entre otras cosas, el negocio que pudieron ser las imprentas decimonónicas, particularmente las de algunos estados, que sobrevivieron gracias a la publicación de una gran cantidad de folletos.

Por lo que respecta a los de reciente adquisición, siguiendo la tradición se ha preferido agruparlos en misceláneas sin ningún orden - creo que el placer que produce al investigador encontrar el folleto deseado donde menos lo espera no se debe impedir-, aunque en un primer momento tuve la intención -y así se llevó a cabo- de agruparlos temáticamente o por autores; los más modernos, sin embargo, permanecen sueltos todavía en cajas de cartón. Casi medio centenar de misceláneas forman parte del fondo rescrvado de la biblioteca por su rareza o importancia; sólo se permite su consulta a profesores, investigadores y estudiantes de posgrado. Sus inmensas posibilidades han comenzado a ser descubiertas no tanto por los abogados - por fuerza centrados en el dere- 
cho vigente-, sino por los historiadores, especialmente los dedicados al estudio de las instituciones y de las ideas. Hasta la fecha, cuando menos cuatro tesis doctorales, alguna de maestría y una extraordinaria investigación a un tiempo bibliográfica y prosopográfica de los abogados mexicanos del siglo XIX - a cargo del profesor Alejandro Mayagoitia- se han elaborado con materiales de esa colección que hoy, "oficialmente", damos a conocer y presentamos a todos los interesados en este material tan lleno de sorpresas y todavía hoy tan celoso de sus secretos.

\section{BIBLIOGRAFÍA}

-Arenal Fenochio, Jaime del, "Hacia el estudio de la folletería jurídica mexicana (1851-1910)", Cuadernos del Instituto de Investigaciones Jurídicas, año 2, núm. 4, enero-abril de 1987, pp. 79-116. grafia", Revista de Investigaciones Jurícticas, año 13, núm. 13, 1989, pp. 197-226. Jacinto Pallares. Maestro y jurista nicolaíta, Gobierno del Estado de Michoacán/Universidad Michoacana de San Nicolás de Hidalgo, Morelia, 1992.

-Bulnes, Francisco, El verdadero Díaz y la revolución, Eusebio Gómez de la Puente, editor, México, 1920.

-Díaz y Díaz, Martín, "El litigio del Tlahualilo: presagio de un derecho de propiedad sin arrogancia", Revista de Inv'estigaciones furídicas, año 14, núm. 14, 1990, pp. 129-194.

-Diego Fernández, Rafael, "La Constitución y la tiranía: un proyecto constitucional razonado de José Diego Fernández Torres", Revista de Investigaciones Juridicas, año 17, núm. 17, 1993, pp. 139-197. -Dorantes, Alma et al., Inventario e indice de las misceláneas de la Biblioteca Pública del Estado de Jalisco, INAH, Guadalajara, 1978, 3 vols.

-Moreno Valle, Lucina, Catálogo de la Colección Lafragua 1821-1853, UNAM, México, 1975. 


\section{SECUENCIA}

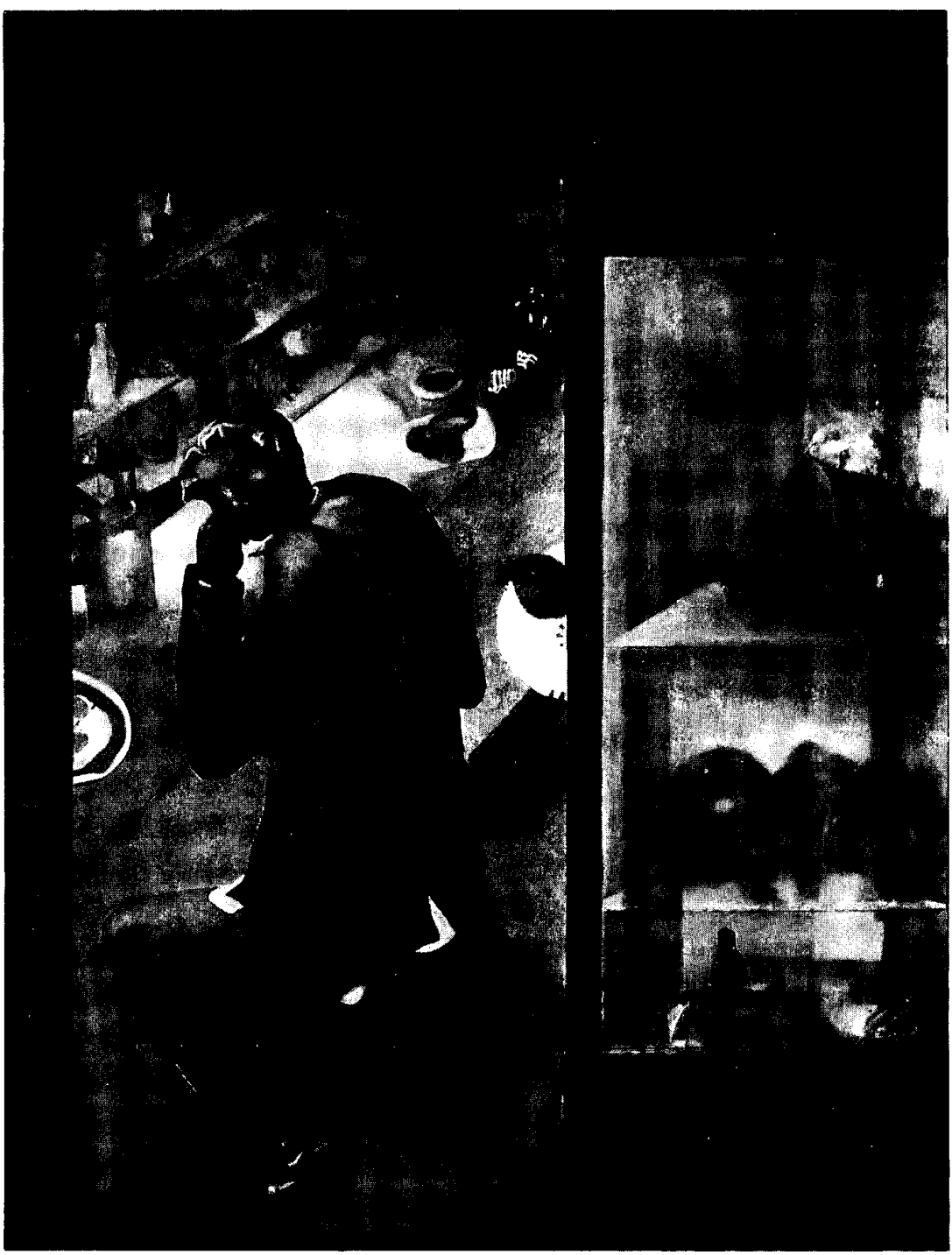

40

Ilustraciones de Adrián Bellón Pérez. Queda estrictamente prohibida la reproducción total o parcial de las imágenes publicadas en este número de la revista Secuencia, 39.

Las imágenes fueron contratadas y/o donadas de forma exclusiva para esta publicación. 